\title{
In vitro antibacterial activity of seven Indian spices against high level gentamicin resistant strains of enterococci
}

\author{
Sharma Revati ${ }^{1}$, Chapagain Bipin², Pai (Bhat) Chitra², Bhattacharjee Minakshi
}

\begin{abstract}
${ }^{1}$ MGM Central Research Laboratory, MGM Medical College and Hospital, Kamothe, India

2Department of Microbiology, MGM Medical College and Hospital, Kamothe, India
\end{abstract}

Submitted: 14 October 2013

Accepted: 23 February 2014

Arch Med Sci 2015; 11, 4: 863-868

DOI: 10.5114/aoms.2015.53307

Copyright @ 2015 Termedia \& Banach

\begin{abstract}
Introduction: The aim of the study was to explore the in vitro antibacterial activity of seven ethanolic extracts of spices against high level gentamicin resistant (HLGR) enterococci isolated from human clinical samples.

Material and methods: Two hundred and fifteen enterococcal strains were isolated from clinical samples. High level gentamicin resistance in ethanolic extracts of cumin (Cuminum cyminum), cinnamon (Cinnamomum zeylanicum), ginger (Zingiber officinale), fenugreek (Trigonella foenum-graecum), cloves (Syzygium aromaticum), cardamom (Elettaria cardamomum Maton) and black pepper (Piper nigrum) were prepared using Soxhlet apparatus. The antibacterial effect of the extracts was studied using the well diffusion method. Statistical analysis was carried out by $\chi^{2}$ test using SPSS 17 software.

Results: Only cinnamon and ginger were found to have activity against all the isolates, whereas cumin and cloves had a variable effect on the strains. Fenugreek, black pepper and cardamom did not show any effect on the isolates. The zone diameter of inhibition obtained for cinnamon, ginger, cloves and cumin was in the range $31-34 \mathrm{~mm}, 27-30 \mathrm{~mm}, 25-26 \mathrm{~mm}$ and $19-20 \mathrm{~mm}$ respectively.

Conclusions: Cinnamomum zeylanicum and Z. officinale showed the maximum antibacterial activity against the enterococcal isolates followed by S. aromaticum and C. cyminum. The findings of the study show that spices used in the study can contribute to the development of potential antimicrobial agents for inclusion in the anti-enterococcal treatment regimen.
\end{abstract}

Key words: kitchen spices, Soxhlet apparatus, antibiotic sensitivity testing.

\section{Introduction}

Enterococci have emerged as an important nosocomial pathogen in the last decade. They can cause a wide variety of infections including urinary tract infections, bacteremia, endocarditis, meningitis and soft tissue infections. Of 47 species known to date, Enterococcus faecalis accounts for approximately $80-90 \%$ of the clinical isolates and E. faecium was found in the remaining cases [1, 2].

The recent interest in Enterococcus is due to the increased incidence of nosocomial infections caused by it throughout the world. It stands second in causing nosocomial infections [3]. Resistance of these organisms to the current and the commonly used antibiotics is

\author{
Corresponding author: \\ Dr. Sharma Revati \\ 404, Angel Ark \\ Sector 8, Kalamboli \\ Navi Mumbai 410218 \\ Maharashtra, India \\ Phone: 09833110502 \\ E-mail: \\ revupattani@gmail.com
}


one of the burning issues globally. The strains of enterococci have intrinsic as well as acquired resistance to most antimicrobial agents [3].

A common regimen for treatment of serious enterococcal infections such as septicemia is the combination of cell wall inhibitors such as penicillin, ampicillin or vancomycin with aminoglycosides such as streptomycin or gentamicin [4]. The addition of a cell wall inhibitor agent helps in the penetration of the aminoglycoside into the bacterial cytoplasm, making the intrinsically resistant organism aminoglycoside sensitive. The presence of high level aminoglycoside resistance (HLAR) in enterococci defined as the minimum inhibitory concentration of aminoglycoside for the isolate makes the synergism of cell wall inhibitor and aminoglycoside ineffective [5].

In recent years, enterococcal isolates demonstrating high level resistance to both streptomycin and gentamicin, conditions that preclude synergistic interactions between cell wall-active antibiotics and available aminoglycosides, have become common in many health settings $[5,6]$. Against such isolates, there is no other combination of antimicrobial agents which reliably provides bactericidal activity.

The possession of diverse virulence factors has been an important benefit for enterococci, since possessing any of them may change the severity of infections caused by these bacteria. On the other hand, it is believed that nosocomial enterococci might have virulence elements that increase their ability to colonize hospitalized patients $[4,8,9]$. Resolution of the high level gentamicin resistant enterococci infections is further complicated by the presence of virulence factors present in these organisms [9].

The shift in the susceptibility of enterococci to antibiotics is a major challenge faced by the medical fraternity and has made the future management of the infections uncertain. Hence it has become the "need of the hour" to find a solution for the growing problem of drug resistance. The increasing failure of antibiotics has led to the screening of several plant extracts for potential antimicrobial activity. If found effective, such alternative antimicrobial agents could be explored further to overcome the problem of microbial drug resistance to antibiotics. To the best of our knowledge no studies have been performed to detect the antimicrobial effect of Indian spices on multi-drug resistant strains of enterococci possessing virulent traits. All the related studies have only dealt with standard strains of enterococci but not with the clinical isolates.

\section{Material and methods}

Over a period of 2 years 10,398 clinical samples from patients (120 males and 95 females) attending the tertiary care center were processed in the microbiology laboratory, out of which 215 strains of enterococci were isolated. The samples including blood, urine, catheter tube tip, sputum, vaginal swabs, body fluids, tip of endotracheal tube, and pus were processed to isolate the above-mentioned enterococcal strains. These isolated strains were considered clinically significant when obtained in pure culture from the clinical samples or in significant numbers as part of mixed cultures. The isolates were further identified in accordance with the standard procedure $[9,10]$.

\section{Presumptive identification}

Samples were cultured on to $5 \%$ blood agar and MacConkey agar. Gram positive cocci showing negative catalase reaction, positive PYR test, black colonies on bile esculin agar and growth in $6.5 \% \mathrm{NaCl}$ broth were presumptively identified as enterococci. Further, growth of the isolates at both $4^{\circ} \mathrm{C}$ and $45^{\circ} \mathrm{C}$ confirmed them to be enterococci. The bacitracin sensitivity test was also done to exclude other Streptococcus species.

\section{Characterization and speciation of isolates}

The isolates which were primarily identified as Enterococcus were then further characterized to the species level with the help of conventional biochemical methods as devised by Facklam and Collins [10]. This was based on fermentation of the carbohydrates by using $1 \%$ solution of the sugars glucose, lactose, raffinose, arabinose, sorbose, sucrose and sorbitol, pyruvate utilization using 1\% pyruvate slant, arginine decarboxylation using Moeller's decarboxylation broth motility test and pigment production using nutrient agar.

\section{Screening of isolates for gentamicin resistance}

The isolates were tested for high level gentamicin resistance by the Kirby-Bauer disc diffusion method. A high level gentamicin disc $(120 \mu \mathrm{g})$ was used for the method. The inoculum was prepared according to the McFarland standard 0.5.

\section{Minimum inhibitory concentration (MIC) testing for gentamicin}

The MIC testing was performed by using Epsilometer test strips for gentamicin which had a range of $0.064-1064 \mu \mathrm{g} / \mathrm{ml}$.

\section{Spices}

Seven types of typical Indian spices and herbs, namely Piper nigrum (black pepper), Cuminum 
cyminum (cumin), Trigonella foenum-graecum (fenugreek), Cinnamomum zeylanicum (cinnamon), Elettaria cardamomum Maton (cardamom), Syzygium aromaticum (cloves) and Zingiber officinale (ginger) in the form of whole fruit, seeds, rhizome, bark, and buds were purchased from a local retail market. All the spices were washed thoroughly with distilled water to make them free from any contaminated particulate matter. The spices were then air dried and used for further procedures.

\section{Extraction of spices}

The extraction of spices was carried out according to a procedure described by Manoj Kumar Singh et al., which is as follows [11].

\section{Preparation of powdered spices}

The air dried materials were powdered using a mixer grinder.

\section{Soxhlet extraction}

One hundred and fifty g of the powdered plant material was subjected to Soxhlet extraction using ethanol $(500 \mathrm{ml})$ as an extracting solvent. The extraction temperature was $78^{\circ} \mathrm{C}$. The time of extraction was 3-6 h or until the color solvent appeared in the siphon. The crude extract was kept at room temperature for ten days to remove any solvent remaining in the extract. The extracts were stored in dark colored bottles, labeled and stored at $4^{\circ} \mathrm{C}$ until use.

\section{Preparation of working solution}

The crude extract was dissolve in dimethyl sulfoxide (DMSO) (10-40\%) by dissolving $1 \mathrm{~g}$ extract in $10 \mathrm{ml}$ of it. The concentration of the stock solution was $100 \mathrm{mg} / \mathrm{ml}$. The solutions were stored in a refrigerator.

\section{Inoculum preparation}

Three or four colonies of bacteria were transferred to a test tube containing $5 \mathrm{ml}$ of sterile nutrient broth. It was incubated at $37^{\circ} \mathrm{C}$ for 3 or $4 \mathrm{~h}$. The tubes were compared with McFarland Nephelometer Standard 0.5 (turbidity standard). A blank nutrient broth was used as a control.

\section{Evaluation of antibacterial activity of spice extracts}

The crude extracts of spices were screened for their antimicrobial activity against the organisms by the agar well diffusion method presented by Dingle et al. [12]. A sterile cotton swab was dipped into the prepared inocula and seeded all over the Mueller Hinton agar plate by rotating through an angle of $60^{\circ}$. After each swabbing, finally the swab was passed round the edges of the agar surface and left to dry for a few minutes at room temperature with the lid closed. Then with the help of a sterile cork borer $(6 \mathrm{~mm})$, wells were made in the inoculated plate and labeled. Fifty $\mu l$ of the working suspensions of the spice extracts were dispensed in the respective wells with the help of the micropipette. The solvent DMSO itself was tested for its activity as a control at the same time. The plates were left for half an hour with the lid closed. Then the plates were incubated at $37^{\circ} \mathrm{C}$ for $24 \mathrm{~h}$. The antibacterial activity was evaluated by measuring the zone of inhibition in millimeters. Tests were carried out in triplicate.

\section{Results}

A total of 215 enterococcal strains were isolated from different clinical samples. Ninety-one (42\%) strains of enterococci were isolated from urine samples, 47 (22\%) from pus, 21 (10\%) from sputum, 18 (8\%) each from blood and catheter tip and 9 (4\%), 6 (3\%), 3 (1\%) and 2 (1\%) from endotracheal tip, pleural fluid, cerebrospinal fluid, and vaginal swabs respectively.

From 215 strains of enterococci, 148 (69\%) strains showed high level gentamicin resistance. Among 148 HLGR, 102 (69\%) and 42 (28\%) were E. faecalis and E. faecium respectively and 4 (3\%) were unusual enterococcal species (Table I).

The result of the disc diffusion method $(120 \mu \mathrm{g})$ was in full concurrence with that of the $E$ test method $(0.016-1064 \mu \mathrm{g})$ in the case of gentamicin. All the $148(69 \%)$ strains which showed HLGR with the HLG disc were resistant at different levels when tested with E-strips. Fifty-six (38\%) of the 148 HLGR enterococci had a MIC of $>1024 \mu \mathrm{g} / \mathrm{ml}$ (Tables II, III).

The antimicrobial activity of the seven spices was tested against the multidrug Enterococ-

Table I. Distribution of high level gentamicin resistance among different species of enterococci using the Kirby-Bauer disc diffusion method

\begin{tabular}{|lccccccc|}
\hline E strip & $\begin{array}{c}\text { E. faecalis } \\
(N=113) \\
n(\%)\end{array}$ & $\begin{array}{c}\text { E. faecium } \\
(N=70) \\
n(\%)\end{array}$ & \multicolumn{5}{c|}{$\begin{array}{c}\text { Non-faecalis and non-faecium } \\
(N=32) \\
n(\%)\end{array}$} \\
\hline HLG & $102(90)$ & $42(60)$ & $\begin{array}{c}\text { E. avium } \\
(n=11)\end{array}$ & $\begin{array}{c}\text { E. casseliflavus } \\
(n=5)\end{array}$ & $\begin{array}{c}\text { E. durans } \\
(n=6)\end{array}$ & $\begin{array}{c}\text { E. gallinarum } \\
(n=21)\end{array}$ & $\begin{array}{c}\text { E. raffinosus } \\
(n=8)\end{array}$ \\
\cline { 3 - 8 } & & & $2(18)$ & 0 & $1(16)$ & 0 & $1(25)$ \\
\hline
\end{tabular}


Table II. High level gentamicin susceptibility pattern of enterococci isolates by Epsilometer test

\begin{tabular}{|lccc|}
\hline Organism & \multicolumn{3}{c|}{ Sensitivity pattern (CLSI) } \\
\hline Enterococci species & Sensitive & Intermediate & Resistant \\
\cline { 2 - 4 } & $<500 \mu \mathrm{g} / \mathrm{ml}$ & - & $>500 \mu \mathrm{g} / \mathrm{ml}$ \\
\cline { 2 - 4 } & $67(31 \%)$ & 0 & $148(69 \%)$ \\
\hline
\end{tabular}

Table III. Distribution of MIC ranges of HLG for various enterococcal species

\begin{tabular}{|lllllllc|}
\hline Enterococci & 128 & 192 & 256 & 384 & 512 & 768 & 1024 \\
\hline $\begin{array}{l}\text { Number of isolates at } \\
\text { specified } \mathrm{MIC}[\boldsymbol{\mu g} / \mathrm{ml}]\end{array}$ & NA & NA & NA & NA & 55 & 37 & 56 \\
\hline
\end{tabular}

cus by using the agar well diffusion assay. The comparative bioactivity of the spices is shown in Figure 1.

The crude ethanolic extract of cinnamon, cloves, ginger, cardamom and cumin showed significant antibacterial activity against all the clinical isolates of enterococci. The spices differed in their antimicrobial effect, as shown in the Figure 2.

The maximum antibacterial effect was shown by cinnamon and ginger with all 215 isolates inhibited when tested with it. The maximum diameter of the zone of inhibition against the isolates was achieved by cinnamon ( $34 \mathrm{~mm}$ ), followed by cloves $(26 \mathrm{~mm})$, ginger $(20 \mathrm{~mm})$, cardamom $(18 \mathrm{~mm})$, and the least was shown by cumin $(14 \mathrm{~mm})$. Fenugreek and black pepper did not have any antibacterial effect on enterococcal isolates.

Tables IV and V show that all the different species of Enterococcus were maximally inhibited by cinnamon and ginger, followed by cloves. Cumin had an inhibitory effect only on one isolate of E. faecalis and E. faecium each, whereas cardamom showed antibacterial activity against seven isolates of $E$. faecalis and one E. faecium isolate.

The $\chi^{2}$ test was employed to compare the antibacterial activities of all the spices. Significant differences in activity were found between cinnamon and cloves $(p=0.03)$, as well as between

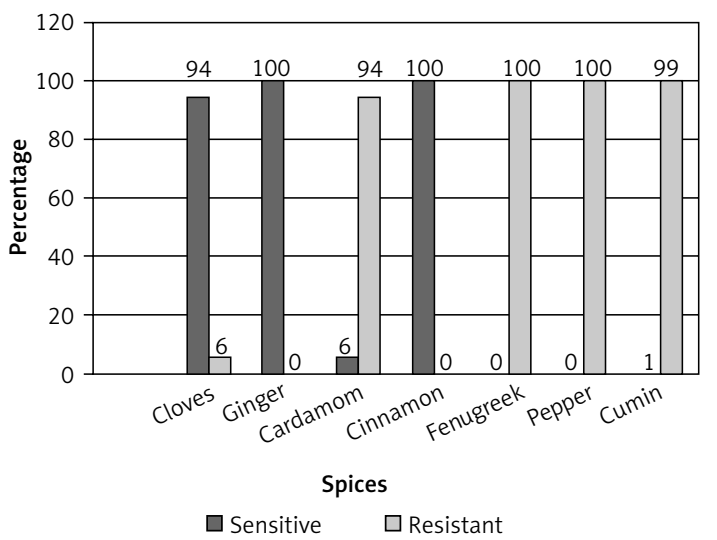

Figure 1. Antimicrobial activity of species (\%) cinnamon and cardamom ( $p=0.020)$. Similarly, a difference in the bioactivity was found for ginger and cloves as well as ginger and cardamom.

\section{Discussion}

It is becoming more and more common to find many bacteria developing resistance to most common antibiotics. Enterococci exhibiting HLGR have been reported as an important cause of hospital acquired infection from many geographical locations, including European countries and the United States $[13,14]$. Gentamicin together with a cell wall active agent is one of the common antibiotics used against serious enterococcal infections [4]. HLGR among enterococci poses a serious therapeutic challenge in such serious diseases [15].

The present study investigated the status of high level gentamicin resistance among the different species of enterococci and studied the bioactivity of seven Indian spices on the HLGR strains. Sixty-nine perect of the 215 enterococcal isolates were resistant to high level gentamicin. The results of the disc diffusion method and $E$ test were in absolute concurrence. It was also seen that $3 \%$ of the unusual species of Enterococcus were also HLGR. We had a clear dominance of HLGR E. faecalis (90\%) followed by HLGR E. faecium (60\%).

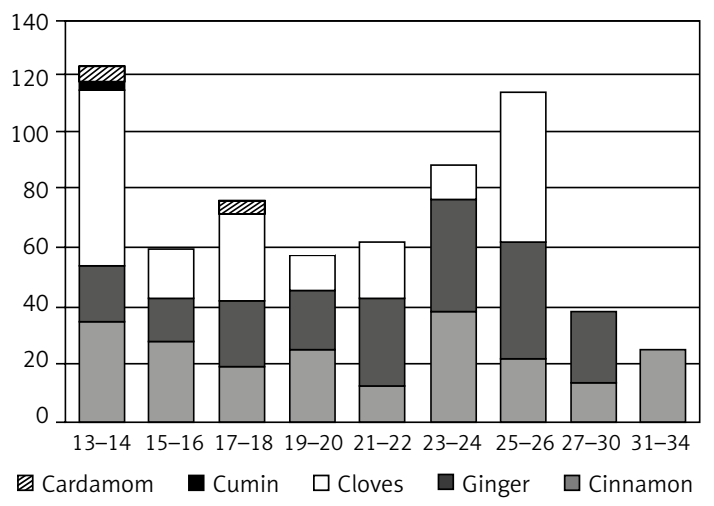

Figure 2. Zone diameter of the 7 spices for enterococci 
Table IV. Antimicrobial sensitivity pattern of different spices for E. faecalis and E. faecium

\begin{tabular}{|lccccccc|}
\hline Organism & Cinnamon & Ginger & Cloves & Cumin & Cardamom & Fenugreek & Pepper \\
\hline E. faecalis $(n=102)$ & $102(100 \%)$ & $102(100 \%)$ & $96(94 \%)$ & $1(1 \%)$ & $7(7 \%)$ & 0 & 0 \\
\hline E. faecium $(n=42)$ & $42(100 \%)$ & $42(100 \%)$ & $40(97 \%)$ & $1(1 \%)$ & $1(4 \%)$ & 0 & 0 \\
\hline
\end{tabular}

Table V. Antimicrobial sensitivity pattern of different spices in unusual enterococcal species

\begin{tabular}{|lccccccc|}
\hline Organism & Cinnamon & Ginger & Cloves & Cumin & Cardamom & Fenugreek & Pepper \\
\hline E. avium $(n=2)$ & $2(100 \%)$ & $2(100 \%)$ & $1(50 \%)$ & 0 & 0 & 0 & 0 \\
\hline E. durans $(n=1)$ & $1(100 \%)$ & $1(100 \%)$ & $1(100 \%)$ & 0 & 0 & 0 & 0 \\
\hline E. raffinosus $(n=1)$ & $1(100 \%)$ & $1(100 \%)$ & $1(100 \%)$ & 0 & 0 & 0 & 0 \\
\hline
\end{tabular}

In this study we also analyzed the antimicrobial effect of cinnamon, cloves, ginger, cumin, black pepper, cardamom and fenugreek seeds. Cinnamon, ginger and cloves showed excellent antimicrobial activity against HLGR enterococci. Cardamom and cumin also showed sensitivity against a few isolates. Black pepper and fenugreek did not show any activity against the isolates. The isolates which showed sensitivity to the spices exhibited a zone diameter of inhibition (ZDI) greater than $7 \mathrm{~mm}$. Cinnamon exhibited the best anti-enterococcal activity, producing ZDI ranging between $31 \mathrm{~mm}$ and $34 \mathrm{~mm}$. By the agar diffusion method, the growth inhibitory activity was followed by the action of ginger with ZDI 25-30 mm; 25 (17\%) were the most sensitive isolates for which the ZDI values were $27-30 \mathrm{~mm}$. The maximum ZDI exhibited by cloves was $25-26 \mathrm{~mm}$ by 52 isolates and by cardamom was $17-18 \mathrm{~mm}$. The isolates showed less sensitivity to Cinnamon (CMN); however, 2 (1\%) of the tested isolates had ZDI $14 \mathrm{~mm}$. Thus, the three spice extracts exhibited different degrees of growth inhibition against enterococcal isolates, and the ranking of anti-enterococcal activity of the extracts tested is cinnamon = ginger $>$ cloves $>$ cardamom $>$ cumin.

Cinnamomum zeylanicum bark is rich in cinnamaldehyde (50.5\%), which has been proven to be active against many pathogenic Gram-positive and Gram-negative bacteria [15, 16]. Ali et al. reported cinnamaldehyde as an active agent to inhibit the growth of both antibioticsensitive and -resistant strains of Helicobacter pylori [17]. It has been reported that $S$. aromaticum oil contains a high level (75\%) of eugenol, and the antibacterial activity of $S$. aromaticum is attributed to this compound $[15,16]$. Another important antimicrobial compound is tannin, in S. aromaticum, which also aids the process of antimicrobial action [17]. The antibacterial activity of $C$. cyminum essential oil is perhaps attributable to the high levels of cumin aldehyde (16.1\%); the other main component is a-pinene (11.4\%). Nanasombat reported that carvone and carvacrol also have inhibitory effects on bacterial strains [18]. Here, we have not studied the antibacterial activity of the components within the extracts; however, the compounds mentioned above may be responsible for the anti-enterococcal activity of the extracts, as has been investigated in our study.

Our study only analyzed the zone of inhibition as a parameter for the antibacterial activity of spices against the isolates. However, for an accurate description of the antimicrobial properties of the spices we suggest performing MIC and Kill kinetics (rate and extent of bacterial killing). Studies have shown that it displays better sensitivity trends to physicians than disc diffusion methods [16]. Time kill experiments should also be considered as a tool to determine whether the activity of the spices is dosage and time dependent so that it would imply a more rational basis for determining the optimal dosage of antimicrobial treatment regimens in order to combat the spread of antimicrobial resistance [16].

In conclusion, $C$. zeylanicum and $Z$. officinale showed the maximum antibacterial activity against the enterococcal isolates, followed by S. aromaticum and $C$. cyminum. The findings of the study show that spices used in the study can contribute to the development of potential antimicrobial agents for inclusion in the anti-enterococcal treatment.

\section{Conflict of interest}

The authors declare no conflict of interest.

\section{References}

1. Brtkova A, Filipova M, Drahovska H, Bujdakova H. Characterization of enterococci of animal and environmental origin using phenotypic methods and comparison with PCR based methods. Veterinarni Medicina 2010; 55: 97-105.

2. Karmakar MG, Edwin SG, Mehta PR. Enterococcal infections with special reference to phenotypic characterization and drug resistance. Indian J Med Res 2004; 119 (Suppl): 22-5. 
3. Sood S, Malhotra M, Das BK, Kapil A. Enterococcal infections and antimicrobial resistance. Indian J Med Res 2008; 128: 111-21.

4. Randhawa VS, Kapoor L, Singh V, Mehta G. Aminoglycoside resistance in enterococci isolated from paediatric septicaemia in a tertiary care hospital in north India. Indian J Med Res 2004; 119 (Suppl): 77-9.

5. Slama B, Saenz Y, Klibi N, et al. Detection of virulence factors in high-level gentamicin-resistant Enterococcus faecalis and Enterococcus faecium isolates from a Tunisian hospital. Can J Microbiol 2007; 53: 372-5.

6. Feizabadi MM, Maleknejad P, Asgharzadeh A, Asadi S, Shokrzadeh L, Sayadi S. Prevalence of aminoglycosidemodifying enzymes genes among isolates of Enterococcus faecalisand Enterococcus faecium in Iran. Microb Drug Resis 2006; 12: 265.

7. Hasani A, Sharifi Y, Ghotaslou R, et al. Molecular screening of virulence genes in high level gentamicin resistant Enterococcus faecalis and Enterococcus faecium isolated from clinical specimen in Northwest Iran. Indian J Med Microbiol 2012; 30: 175-81.

8. Jain S, Kumar A, Kashyap B, Kaur IR. Clinico-epidemiological profile and high-level aminoglycoside resistance in enterococcal septicemia from a tertiary care hospital in east Delhi. Int J Appl Basic Med Res 2011; 1: 80-3.

9. Jayanthi S, Ananthasubramanian N, Appalaraju B. Assessment of pheromone response in biofilm forming clinical isolates of high level gentamycin resistant Enterococcus faecalis. Indian J Med Microbiol 2008; 23: 248-51.

10. Facklam RR, Collins MD. Identification of enterococcus species isolated from human infection by a conventional test scheme. J Clin Microbiol 1989; 27: 731-4.

11. Singh MK, Singh N. Comparison of antimicrobial activity of herbs and spices and their phytochemical determination. Int J Green Pharm 2011; 5: 229-35.

12. Dingle J, Reed WW, Solomons GL. The enzymatic degradation of pectin and other polysaccharides II. Application of the cup assay method to the estimation of enzyme. J Sci Food Agriculture 1953; 4: 149-53.

13. Daikos GL, Bamias G, Kattamis C, et al. Structure locations and transfer frequencies of genetic elements conferring high level gentamicin resistance in enterococcus faecalis isolates. Antimicrob Agents Chemother 2003; 47: 3950-3.

14. Sader HS, Pfaller MA, Tenover FC, et al. Evaluation and characterization of multiresistant Enterococcus faecium from 12 U.S. medical centers. J Clin Microbiol 1994; 32: 2840-2.

15. Chow JW. Aminoglycoside resistance in enterococci. Clin Infect Dis 2000; 31: 586-9.

16. Mandal S, Debmandal M, Saha K, Pal NK. In vitro antibacterial activity of three Indian spices against methicillin-resistant Staphylococcus aureus. Oman Med J 2011. 26: 319-23.

17. Ali SM, Khan AA, Ahmed I, et al. Antimicrobial activities of Eugenol and Cinnamaldehyde against the human gastric pathogen Helicobacter pylori. Ann Clin Microbiol Antimicrob 2005; 20: 4-20.

18. Nanasombat S. Antibacterial activity of crude ethanolic extracts and essential oils of spices against salmonellae and other enterobacteria. KMITL Sci Tech J 2005; 5: 527-38. 